\title{
Lâminas de irrigação para produção de batata-semente em plântulas propagadas in vitro
}

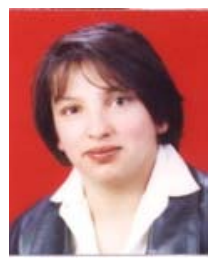

\author{
Angela P. Nogales ${ }^{1}$, René C. Rivera ${ }^{2} \&$ Sergio N. Duarte ${ }^{3}$ \\ 1 Consultora em Cultura de Tecidos. Rua 2, Pasaje 2, n 42, Villa Armonia, La Paz, Bolívia. Fone: (5912) $225-0194$. \\ E-mail: anpal98@hotmail.com (Foto) \\ 2 DER/ESALQ/USP. Av. Pádua Dias 11, CEP 13418-900, Piracicaba, SP. Fone: (19) 3429-4217, Fax: (19) 3435-1840. \\ E-mail: rncriver@carpa.ciagri.usp.br \\ 3 DER/ESALQ/USP. E-mail: snduarte@carpa.ciagri.usp.br
}

Protocolo $49-8 / 5 / 2002$

\begin{abstract}
Resumo: Avaliaram-se, neste trabalho, três lâminas de irrigação (75, 100 e 125\% da ETc, correspondentes aos tratamentos $\mathrm{T}_{1}, \mathrm{~T}_{2}$ e $\mathrm{T}_{3}$, respectivamente) para produção de semente básica de batata (Solanum ssp) sob condições de estufa, a partir de plantas propagadas in vitro. 0 estudo se realizou na localidade de Viacha, próximo à cidade de La Paz, Bolívia. Os teores de água no solo foram elevados nos três tratamentos, mas se mantiveram com valores adequados para o desenvolvimento de plântulas de batata propagadas in vitro, sendo que o rendimento dos tubérculos não variou significativamente nos três tratamentos, alcançando-se 1,07, 1,03 e $0,92 \mathrm{~kg} \mathrm{~m}^{-2}$ para $T_{3}, T_{2}$ e $T_{1}$, respectivamente. Por outro lado, houve diferenças significativas nas eficiências de uso da água, obtendo-se para $T_{2}$, o maior índice.
\end{abstract}

Palavras-chave: tubérculos, estufa, eficiência do uso da água

\section{Water depths for production of potatos seed by seedlings propagated in vitro}

\begin{abstract}
The objective of this work was to evaluate three irrigation water depths 175,100 and $125 \%$ of ETc, corresponding to treatments $T_{1}, T_{2}$ and $T_{3}$, respectively) for potato seed (Solanum $s p p)$ production under greenhouse conditions. The study was conducted at Viacha locality, near La Paz, in Bolivia. Soil water content was high for all the treatments but adequate for the development of plants propagated in vitro. Tuber productivity did not vary significantly and was 1.07, 1.03 and $0.92 \mathrm{~kg} \mathrm{~m}^{-2}$ for $T_{3}, T_{2}$ and $T_{1}$ treatments respectively. On the other hand the water use efficiency varied significantly and was the highest for $T_{2}$ treatment.
\end{abstract}

Key words: tuber, greenhouse, water use efficiency

\section{INTRODUÇÃO}

O cultivo da batata (Solanum spp) na Bolívia se constitui em uma atividade de grande importância, tanto no ponto de vista social como econômico. Aproximadamente $60 \%$ das famílias de agricultores dos altiplanos e dos vales cultivam este produto, ocupando 131.787 ha, obtendo uma produtividade média de 4,481 tha ${ }^{-1}$, com produção de 590.530 t. A batata está inclusa entre as cinco culturas mais importantes do país, dentre as quais se citam o trigo, o milho, o arroz e a cevada.

As baixas produtividades obtidas se devem a fatores adversos, como o déficit hídrico, doenças, pragas, nematóides e problemas climáticos. Pesa, ainda, o fato de a batata ser uma cultura de reprodução vegetativa e seu rendimento afetado pelo uso de sementes contaminadas com doenças.

Neste sentido, a micropropagação da batata, através da técnica de cultura de tecidos, apresenta-se como ferramenta importante na produção de sementes com alto grau de pureza varietal e de qualidade fitossanitária, principalmente livres de vírus; porém, dentre os níveis em que se insere a produção de sementes deste tubérculo, a categoria de semente básica é uma das mais críticas devido ao fato de que uma alta porcentagem de plântulas micropropagadas é perdida na fase de aclimatização, em razão do efeito da mudança brusca das condições in vitro para a situação posterior, sendo as plântulas sensíveis ao estresse do meio ambiente, principalmente ao estresse hídrico. Segundo Doorembos \& Kassam (1986) a batata é relativamente sensível ao déficit hídrico durante os estádios de estolonização, início da formação e crescimento dos tubérculos.

Gandar \& Tanner (1976) citam que o alongamento da folha da batata começa a reduzir-se com um potencial de água no solo, de cerca de -0,3 MPa e, no campo, a -0,5 MPa. Esse alongamento cessa completamente e há indícios concretos de 
que os estômatos começam a fechar a -0,35 MPa e a redução da fotossíntese a -0,6 MPa. Em dias com alta evapotranspiração média, o potencial da água na folha baixa a - $0,35 \mathrm{MPa}$, de modo que há uma utilização de apenas uma pequena parte da água do solo.

De acordo com Fabeiro et al. (2001) a produção de tubérculos em sistemas convencionais é altamente influenciada pelo volume total de água aplicada na irrigação. As plantas que sofrem déficit durante a última etapa do seu ciclo reduzem sua produção; se o estresse ocorre na etapa de crescimento, acarreta a obtenção de maior número de tubérculos pequenos. Bosnjak \& Peijic (1996) constataram que a necessidade de água para a batata varia de 460 a $480 \mathrm{~mm}$, ocorrendo aumento de produtividade devido à irrigação de 45 a $72 \%$. Por outro lado, Zhivkov \& Kaltcheva (1997) determinaram que a redução da irrigação em 20, 40 e 60\% produziu perdas de produção de 13 , 18 e $23 \%$, respectivamente. Esses autores, entretanto, não trabalharam com plantas propagadas in vitro.

Tendo em vista esses aspectos buscou-se, com este estudo, determinar a lâmina ótima de irrigação para a produção de batata-semente (semente básica) (Solanum tuberosum spp. andigenum) variedade Waycha, a partir de plântulas propagadas in vitro, sob condições de estufa.

\section{MATERIAL E MÉTODOS}

O trabalho experimental se realizou no Centro de Investigaciones Nucleares (CIN-Viacha) que se encontra a $30 \mathrm{~km}$ a sudoeste da cidade de La Paz, localizado em Viacha, Província de Ingavi. As coordenadas geográficas são 16³9'de latitude Sul e $68^{\circ} 18^{\prime}$ de longitude Oeste, a $3.853 \mathrm{~m}$ de altitude. O clima da localidade é temperado, frio de altitude; a precipitação média anual é de $542 \mathrm{~mm}$, temperatura média anual de $7,1^{\circ} \mathrm{C}$, umidade relativa média anual de $57,8 \%$, evaporação de $4,7 \mathrm{~mm} \mathrm{~d}^{-1}$, velocidade do vento de $8,7 \mathrm{~km} \mathrm{~h}^{-1}$ e $200 \mathrm{~d}$ com geadas.

Foram utilizadas plântulas de batata (Solanum andigenum) variedade Waycha propagadas in vitro. A escolha desta variedade ocorreu devido à sua ampla adaptação, rusticidade e boa produtividade, além da grande aceitação do mercado.

\section{Análise físico-química do substrato}

O substrato utilizado pertencia à classe textural franco7 argilo-arenosa, com densidade aparente de $1,10 \mathrm{~kg} \mathrm{dm}^{-3}$, correspondendo a solos com bastante matéria orgânica e densidade real de 2,42 $\mathrm{kg} \mathrm{dm}^{-3}$. $\mathrm{O} \mathrm{pH}$ encontrado foi de 5,9 (moderadamente ácido) e a condutividade elétrica do extrato de saturação do solo foi de $0,565 \mathrm{dS} \mathrm{m}^{-1}$, o que indica que não existiram problemas de salinidade. A capacidade de troca catiônica deu como resultado 20,639 $\mathrm{cmol}_{\mathrm{c}} \mathrm{kg}^{-1}$ de solo. Encontrou-se uma quantidade total de fósforo de 7,11 ppm, considerado nível médio, o que motivou a aplicação adicional de fertilizantes ao substrato, a fim de se alcançar teores de fósforo apropriados. $\mathrm{O}$ conteúdo de nitrogênio encontrado foi de $0,51 \%$. Esses valores são típicos para solos com elevado conteúdo de matéria orgânica.

\section{Análise química da água de irrigação}

Segundo a relação de adsorção de sódio (RAS) e a condutividade elétrica $\left(0,126 \mathrm{dS} \mathrm{m}^{-1}\right)$ a água pertencia à classe $\mathrm{C}_{1} \mathrm{~S}_{1}$ (água de baixa salinidade e sodicidade, podendo ser usada na maioria das culturas e solos). Também, os teores de cloreto e nitrato não apresentaram índices de toxicidade. $\mathrm{O} \mathrm{pH}(8,1)$ revelou-se ligeiramente alcalino.

\section{Metodologia}

O estudo se desenvolveu na época de verão, em uma estufa com cobertura plástica de "duas águas". O substrato orgânico foi disposto em três canteiros de $5 \mathrm{~m}^{2}$ cada um. O delineamento utilizado foi inteiramente casualizado. Os tratamentos considerados tiveram somente 3 repetições, devido ao reduzido número de plântulas produzidas experimentalmente nessa época, e foram os seguintes:

- Tratamento $1\left(\mathrm{~T}_{1}\right): \mathrm{ETc}=$ ETo Kc $(75 \%)$

- Tratamento $2\left(\mathrm{~T}_{2}\right): \mathrm{ETc}=$ ETo Kc $(100 \%)$

- Tratamento $3\left(\mathrm{~T}_{3}\right): \mathrm{ETc}=$ ETo Kc $(125 \%)$

em que ETc é a evapotranspiração real da cultura da batata $\left(\mathrm{mm} \mathrm{d}^{-1}\right)$, ETo é a evapotranspiração de referência $\left(\mathrm{mm} \mathrm{d}^{-1}\right) \mathrm{e}$ Kc é o coeficiente da cultura (adimensional). As plântulas foram transplantadas quando tinham altura média de $0,09 \mathrm{~m}$, utilizando-se o espaçamento de 0,15 por $0,15 \mathrm{~m}$; para tal, foram utilizadas 30 bandejas, cada uma com 25 plântulas, utilizandose cerca de 750 plântulas no total.

\section{Manejo da irrigação}

Determinação da evapotranspiração da cultura: A lâmina de irrigação foi determinada a partir da evapotranspiração (calculada diariamente) sendo o turno de rega igual a dois dias. A aplicação de água foi feita por meio de uma proveta graduada. No cálculo da evapotranspiração de referência (ETo) utilizouse o método de Penman-Monteith preconizado pela FAO, sendo os parâmetros necessários para aplicação do método medidos dentro da estufa. Evangelista (1999) considerou este método como padrão, ao comparar vários métodos de estimativa de ETo em estufas, cuja equação é a seguinte:

$$
\text { ETo }=\frac{0,408 \Delta(\mathrm{Rn}-\mathrm{G})+\gamma\left(\frac{900}{\mathrm{~T}+273}\right) \mathrm{U}_{2}(\text { ea }- \text { ed })}{\Delta+\gamma\left(1+0,34 \mathrm{U}_{2}\right)}
$$

em que:

ETo - evapotranspiração de referência, $\mathrm{mm} \mathrm{d}^{-1}$

$\mathrm{Rn}$ - saldo de radiação da superfície evaporante, $\mathrm{MJ} \mathrm{m}^{-2} \mathrm{~d}^{-1}$

$\mathrm{G} \quad$ - taxa de fluxo de calor do solo, $\mathrm{MJ} \mathrm{m}^{-2} \mathrm{~d}^{-1}$

$\mathrm{T}$ - temperatura do ar a $2 \mathrm{~m}$ de altura, ${ }^{\circ} \mathrm{C}$

$\mathrm{U}_{2}$ - velocidade do vento a $2 \mathrm{~m}$ de altura, $\mathrm{m} \mathrm{s}^{-1}$

ea-ed - déficit de pressão de vapor a $2 \mathrm{~m}$ de altura, $\mathrm{kPa}$

$\Delta$ - declinação da curva de saturação do vapor d'água, $\mathrm{kPa}{ }^{\circ} \mathrm{C}^{-1}$

$\gamma \quad$ - fator psicrométrica, $\mathrm{kPa}^{\circ} \mathrm{C}^{-1}$

Os valores de Kc da cultura foram também determinados pela metodologia proposta pela $\mathrm{FAO}$, e seus valores foram: 0,$595 ; 0,758 ; 0,795 ; 0,538$ e 0,409 , para os estádios de estolonização, tuberização, prefloração, floração e maturação, respectivamente. Após essas determinações, procedeu-se ao cálculo da ETc. 
Controle da umidade do solo: Para o controle da tensão da água do solo, instalaram-se três tensiômetros, um por cada tratamento, localizados a $0,10 \mathrm{~m}$ de profundidade, em que as raízes das plântulas apresentavam crescimento mais ativo. As leituras foram tomadas diariamente.

Curva de retenção da água no solo: Para a obtenção da curva de retenção, utilizaram-se placas e membranas de pressão de Richards. As tensões $(\psi \mathrm{m})$ consideradas foram as seguintes: 0,$005 ; 0,015 ; 0,025 ; 0,030 ; 0,035 ; 0,045 ; 0,055 ; 0,065 ; 0,075 ; 0,100$; 0,$500 ; 1,000$ e $1,500 \mathrm{MPa}$. A curva de retenção foi ajustada ao modelo proposto por van Genuchten (1980), encontrando-se valores de $0,007332,1,646166$ e 0,392528 para os parâmetros $\alpha$, n e m, respectivamente (Fig. 1).

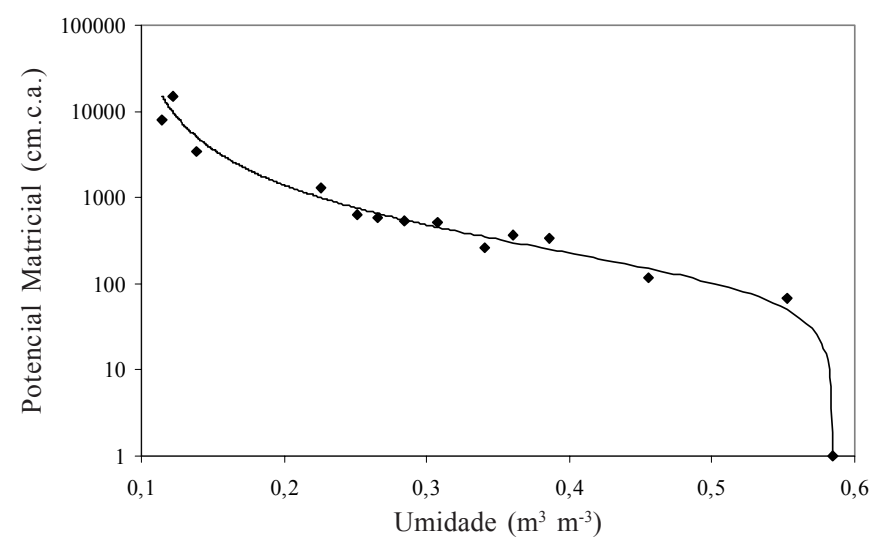

Figura 1. Curva de retenção de água do substrato

As variáveis medidas para se avaliar a resposta da cultura foram peso e diâmetro dos tubérculos, peso da parte aérea e eficiência do uso da água.

\section{RESULTADOS E DISCUSSÃO}

Variação dos elementos meteorológicos dentro e fora da estufa

A Tabela 1 apresenta os valores médios dos elementos meteorológicos registrados durante o período de desenvolvimento do experimento.

Tabela 1. Valores médios dos elementos meteorológicos medidos dentro e fora da estufa: temperatura máxima (TM), temperatura mínima (Tm) e umidade relativa(UR)

\begin{tabular}{|c|c|c|c|c|c|c|c|}
\hline \multirow{2}{*}{$\begin{array}{c}\text { Estádios de } \\
\text { Desenvolvimento } \\
\text { da Cultura }\end{array}$} & \multicolumn{3}{|c|}{ Dentro da Estufa } & \multicolumn{4}{|c|}{ Fora da Estufa } \\
\hline & $\begin{array}{r}\mathrm{TM} \\
\left({ }^{\circ} \mathrm{C}\right)\end{array}$ & $\begin{array}{c}\mathrm{Tm} \\
\left({ }^{\circ} \mathrm{C}\right)\end{array}$ & $\begin{array}{l}\text { UR } \\
(\%)\end{array}$ & $\begin{array}{l}\mathrm{TM} \\
\left({ }^{\circ} \mathrm{C}\right)\end{array}$ & $\begin{array}{r}\mathrm{Tm} \\
\left({ }^{\circ} \mathrm{C}\right)\end{array}$ & $\begin{array}{l}\text { UR } \\
(\%)\end{array}$ & $\begin{array}{l}\text { Horas } \\
\text { de Sol }\end{array}$ \\
\hline Estolonização & 30 & 8 & 53 & 18 & 4 & 47 & 6,45 \\
\hline Tuberização & 30 & 8 & 59 & 17 & 4 & 48 & 5,08 \\
\hline Prefloração & 28 & 7 & 55 & 16 & 4 & 49 & 6,28 \\
\hline Floração & 31 & 8 & 59 & 16 & 4 & 52 & 6,65 \\
\hline Final & 31 & 4 & 43 & 18 & 0 & 43 & 8,10 \\
\hline Média & 30 & 7 & 54 & 17 & 3 & 48 & 7,00 \\
\hline
\end{tabular}

Observou-se que as temperaturas registradas dentro da estufa foram superiores as do exterior, devido à dupla cobertura plástica as quais, por suas características, têm a propriedade de ser relativamente opacas às radiações de onda longa emitida pelo solo, o que provocou diferença de temperatura do interior para o exterior, de $13{ }^{\circ} \mathrm{C}$, no que diz respeito às máximas, e $4{ }^{\circ} \mathrm{C}$, no que se refere às mínimas.

A umidade relativa registrada dentro da estufa durante todo o ciclo, teve pouca variação e foi superior à registrada no exterior, em $6 \%$. Este resultado se deve ao fato de que, dentro da estufa, os intercâmbios gasosos são menores ocorrendo, portanto, uma acumulação de vapor de água.

Em relação às horas de sol, observou-se grande variação em razão de ocorrência de dias em que se alcançou uma insolação em torno de $11 \mathrm{~h}$, enquanto em outros esta foi praticamente zero, devido à nebulosidade, característica da época. Nas outras épocas do ano o desenvolvimento das plantas fica comprometido pelas baixas temperaturas, mesmo dentro de casas-de-vegetação.

\section{Evapotranspiração da cultura}

A Figura 2 apresenta os valores de ETc registrados ao longo de todo o ciclo da cultura. No estádio de estolonização, registrou-se uma ETc média de 2,16 $\mathrm{mm} \mathrm{d}^{-1}$, valor este inferior ao das outras fases, em razão da menor área foliar. No estádio de tuberização, a ETc alcançou valor médio de 2,55 $\mathrm{mm} \mathrm{d}^{-1}$. Os valores mais elevados da ETc ocorreram no início do estádio de prefloração (77 dias após o transplantio) com valor médio de $2,90 \mathrm{~mm} \mathrm{~d}^{-1}$.

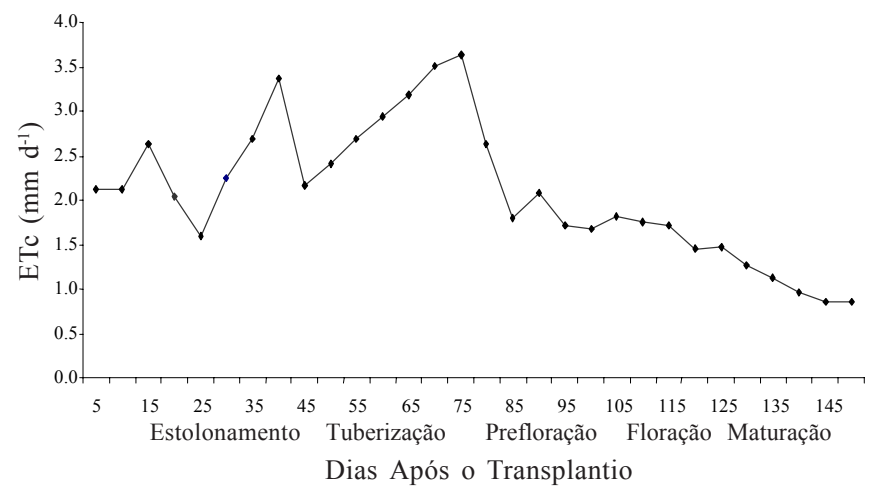

Figura 2. Evapotranspiração da cultura ao longo do ciclo

\section{Lâminas de irrigação}

Com os valores de ETc, procedeu-se ao cálculo das lâminas de irrigação para os três tratamentos, cujos resultados são apresentados na Tabela 2. Verifica-se que foi aplicada uma lâmina total de irrigação de 229,45 mm em T ; 305,93 mm em T e $384,40 \mathrm{~mm} \mathrm{em} \mathrm{T}_{3}$, para um ciclo de $150 \mathrm{~d}$, valores estes menores que os sugeridos por Doorembos \& Kassam (1986) mas para outras condições, enquanto Bezerra (1995) conseguiu rendimento maior com uma lâmina de $214,1 \mathrm{~mm}$, porém para um ciclo de 60 d em uma região tropical.

Segundo a análise de variância (Tabela 3) e o teste de Duncan, observou-se que houve diferenças significativas entre tratamentos no nível de $5 \%$ de probabilidade, sendo $\mathrm{T}_{1}$ inferior aos outros dois tratamentos e $\mathrm{T}_{2}$ menor que $\mathrm{T}_{3}$.

\section{Umidade e tensão da água no solo}

Em geral, a umidade foi maior em $\mathrm{T}_{3}$, variando de 0,37 a $0,56 \mathrm{~m}^{3} \mathrm{~m}^{-3}$, ou seja, manteve-se em torno do ponto de saturação. 
Tabela 2. Lâminas de irrigação aplicadas à cultura da batata nos diferente tratamentos

\begin{tabular}{lccr}
\hline \multirow{2}{*}{ Estádios } & \multicolumn{3}{c}{ Lâmina de Irrigação - mm } \\
\cline { 2 - 4 } & \multicolumn{1}{c}{$\mathrm{T}_{1}$} & \multicolumn{1}{c}{$\mathrm{T}_{2}$} & \multicolumn{1}{c}{$\mathrm{T}_{3}$} \\
\hline Estolonização & 44,12 & 58,82 & 73,53 \\
Tuberização & 56,17 & 74,90 & 93,62 \\
Prefloração & 63,08 & 84,11 & 105,13 \\
Floração & 37,61 & 50,15 & 62,69 \\
Final & 28,47 & 37,96 & 47,45 \\
Total & 229,45 & 305,93 & 382,40 \\
\hline
\end{tabular}

Tabela 3. Análise de variância para as lâminas totais de irrigação

\begin{tabular}{lcccc}
\hline \multicolumn{1}{c}{ Fonte } & G. L. & S .Q. & Q.M. & F. C. \\
\hline Tratamento & 2 & 6652,94 & 1663,23 & 6,62 \\
Resíduo & 6 & 2512,45 & 251,25 & \\
Total & 8 & 4140,49 & & \\
\hline
\end{tabular}

Com relação a $T_{2}$, a umidade também se manteve próximo à saturação, com exceção do primeiro (estolonização) e último (maturação) estádios. $T_{1}$ se manteve inferior à saturação, mas superior à capacidade de campo (umidade de $0,34 \mathrm{~m}^{3} \mathrm{~m}^{-3}$ ) com umidades variando entre 0,24 e $0,55 \mathrm{~m}^{3} \mathrm{~m}^{-3}$ (Fig. 3).

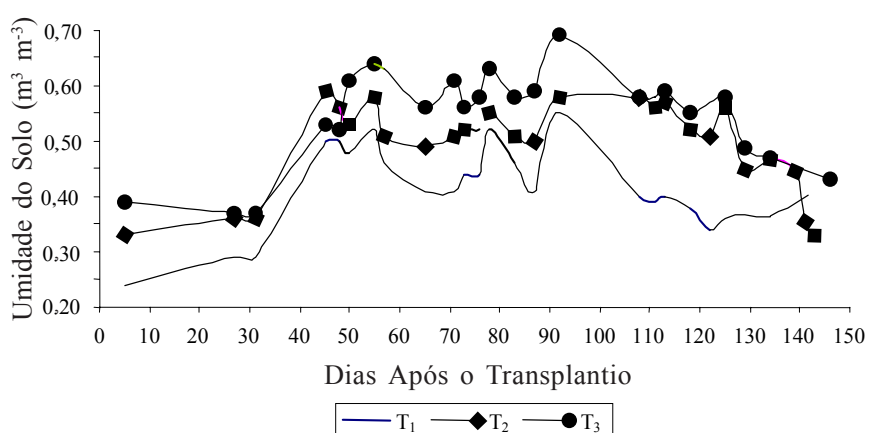

Figura 3. Variação da umidade do solo para os diferentes tratamentos ao longo do ciclo da cultura

A respeito do potencial matricial, em geral este se manteve acima de -0,025 $\mathrm{MPa}$, para os três tratamentos, sendo que em $\mathrm{T}_{3}$ se registraram as maiores tensões, flutuando entre - 0,03 e $0 \mathrm{MPa}$. Tal como ocorrido com a umidade, os valores de tensão foram menores em $\mathrm{T}_{2}$ e $\mathrm{T}_{1}$ (Fig. 4). Verifica-se que as lâminas de água aplicadas nos três tratamentos foram elevadas, porém Kashyap et al. (2001) afirmam que o desenvolvimento das plântulas nessas condições é favorecido por uma alta umidade no solo, pois por serem os estômatos ainda pouco funcionais, ocorre uma excessiva transpiração.

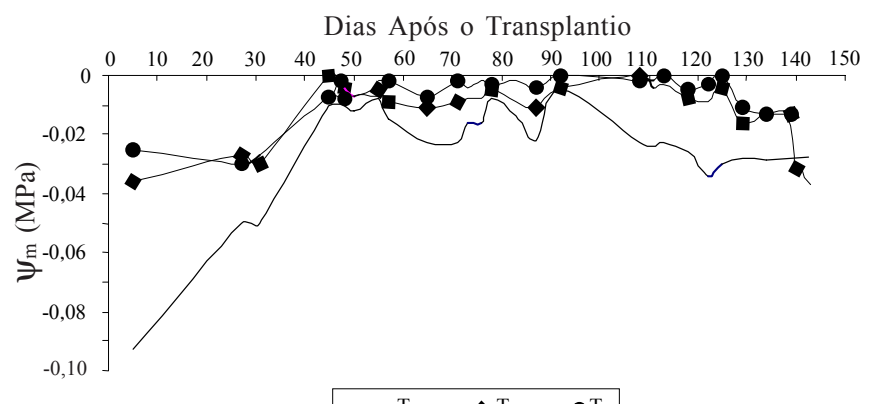

Figura 4. Variação do potencial matricial da água do solo para os diferentes tratamentos ao longo do ciclo da cultura

\section{Variáveis de resposta da cultura}

Relação entre tubérculos e parte aérea: Na Figura 5 constatase estreita relação entre a massa dos tubérculos e a massa da parte aérea, expressas em base de matéria seca. Esta tendência foi observada em todas as repetições, possivelmente por que uma parte aérea maior implica em uma também maior atividade fotossintética, incrementando-se a produção de carboidratos que se acumulam nos tecidos de reserva, que são os tubérculos.

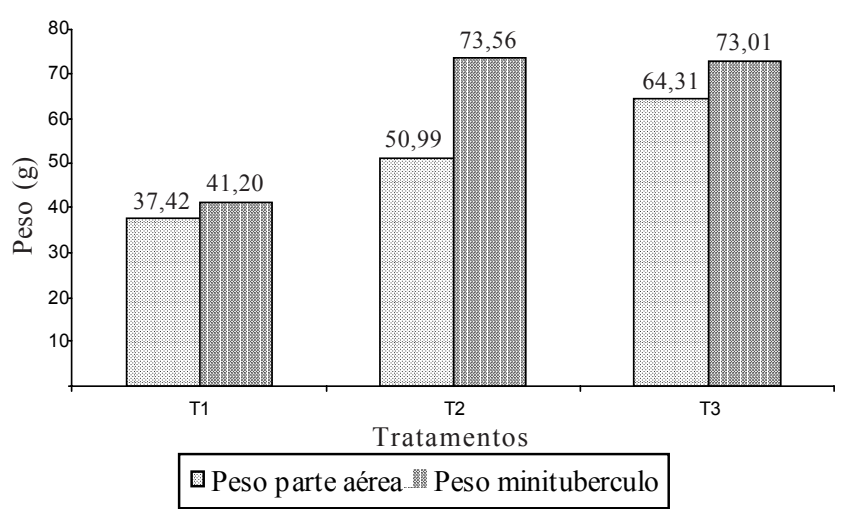

Figura 5. Relação entre o peso seco da parte aérea e o peso seco dos tubérculos para os distintos tratamentos

Produtividade Total: A produtividade média de tubérculos de batata para os diferentes tratamentos é mostrada na Tabela 4 e, de acordo a análise de variância, verificou-se que não houve diferenças significativas entre os fatores, o que indica que as lâminas de irrigação aplicadas à cultura tiveram o mesmo efeito na produção de tubérculos.

Tabela 4. Produtividade média da batata para diferentes lâminas de irrigação

\begin{tabular}{cc} 
Tratamentos & Produtividade $\left(\mathrm{kg} \mathrm{m}^{-2}\right)$ \\
\hline $\mathrm{T}_{1}$ & 1,07 \\
$\mathrm{~T}_{2}$ & 1,03 \\
$\mathrm{~T}_{3}$ & 0,92 \\
\hline
\end{tabular}

As produtividades estão relacionadas com o número de tubérculos produzidos. Netto (1999) destaca que existe decréscimo da razão tubérculo-parte aérea, de modo que, quanto maior o desenvolvimento da parte aérea, menor a produção de tubérculos. Por outro lado, Kincaid et al. (1993) realizando trabalho similar, observaram que os resultados de produtividade não foram afetados significativamente pelas lâminas aplicadas durante o ciclo da cultura, porém Bosnjak et al. (1997) determinaram que o limite inferior ótimo de umidade do solo para se obter rendimentos elevados, é de 75 a 80\% da capacidade de campo. Por sua vez, Nimah et al. (2000) afirmam que uma aplicação de água menor que 53\% da ETc ocasiona uma redução considerável na produtividade.

Classificação dos tubérculos por diâmetro: A produção dos tubérculos por classe de diâmetro, segundo os diferentes tratamentos, é apresentada na Tabela 5. Salienta-se que não se obteve semente básica da Classe I (diâmetro do tubérculo maior a $55 \mathrm{~mm}$ ) que seria o mais desejável, sendo a Classe III a de maior predominância. 
Tabela 5. Classificação dos tubérculos segundo seu diâmetro*

\begin{tabular}{cccc}
\hline \multirow{2}{*}{ Tratamento } & $\begin{array}{c}\text { Classe II } \\
(45-55 \mathrm{~mm})\end{array}$ & $\begin{array}{c}\text { Classe III } \\
(35-45 \mathrm{~mm})\end{array}$ & $\begin{array}{c}\text { Classe IV } \\
(20-30 \mathrm{~mm})\end{array}$ \\
\cline { 2 - 4 } & \multicolumn{4}{c}{ g por Tratamento } \\
\hline $\mathrm{T}_{1}$ & $21,21 \mathrm{~b}$ & $478,79 \mathrm{a}$ & $416,16 \mathrm{a}$ \\
$\mathrm{T}_{2}$ & $11,11 \mathrm{~b}$ & $556,57 \mathrm{a}$ & $461,62 \mathrm{a}$ \\
$\mathrm{T}_{3}$ & $97,78 \mathrm{a}$ & $624,24 \mathrm{a}$ & $348,48 \mathrm{a}$ \\
\hline
\end{tabular}

A análise de variância e o teste de Duncan efetuados indicam diferenças significativas no nível de $5 \%$ de probabilidade para a classe II, mostrando que as lâminas de irrigação tiveram influência sobre a produção nesta classe. $\mathrm{T}_{3}$ é o tratamento que alcançou uma produção maior de tubérculos para este tamanho, cujos resultados podem ser devidos ao fato das plantas terem uma disponibilidade maior de água para suprir a alta demanda evapotranspirativa, fato que caracteriza as plantas propagadas in vitro.

Eficiência do uso de água: Observa-se, na Tabela 6, a média da eficiência de uso de água (EUA) obtida em cada tratamento a partir da produção de matéria seca dos tubérculos, em função do volume de água aplicado.

Tabela 6. Comparação da eficiência de uso de água (EUA) entre os tratamentos*

\begin{tabular}{ccc}
\hline Tratamento & $\begin{array}{c}\text { EUA } \\
\left(\mathrm{kg} \mathrm{MS} \mathrm{m}^{-3}\right)\end{array}$ & $\begin{array}{c}\text { Quantidade de Água } \\
\left(\mathrm{L} \mathrm{kg}^{-1} \mathrm{MS}\right)\end{array}$ \\
\hline $\mathrm{T}_{1}$ & $2,00 \mathrm{~b}$ & 500,00 \\
$\mathrm{~T}_{2}$ & $2,97 \mathrm{a}$ & 336,70 \\
$\mathrm{~T}_{3}$ & $2,12 \mathrm{~b}$ & 471,70 \\
\hline
\end{tabular}

* Médias seguidas de mesma letra não diferem entre si pelo teste de Duncam (5\%)

Para as condições em que se realizou o estudo e segundo a análise estatística para uma probabilidade de $5 \%, \mathrm{~T}_{2}$ teve uma EUA superior aos demais tratamentos, sendo que para se produzir um kg de matéria seca (MS) de tubérculo, utilizaram-se 336,70 L de água; entretanto $\mathrm{T}_{1}$ e $\mathrm{T}_{3}$ não mostraram diferenças significativas na produção de matéria seca em função da lâmina d'água aplicada.

Ressalta-se que os três tratamentos tiveram uma EUA superior à indicada por Hoffman et al. (1990) que encontraram uma EUA de 1,74 $\mathrm{kg} \mathrm{MS} \mathrm{m}^{-3}$, ou seja, uma necessidade de $574,71 \mathrm{~L}$ de água por cada $\mathrm{kg}$ de MS.

\section{CONCLUSÕES}

1. A umidade elevada do solo se manteve em faixas adequadas para o desenvolvimento de plântulas de batata propagadas in vitro.

2. A produtividade de tubérculos não variou significativamente para os diferentes tratamentos, alcançando-se 1,07; 1,03 e $0,92 \mathrm{~kg} \mathrm{~m}^{-2}$ para $\mathrm{T}_{3}, \mathrm{~T}_{2}$ e $\mathrm{T}_{1}$, respectivamente.
3. Houve diferenças significativas nas eficiências de uso da água, obtendo-se para $T_{2}$ o maior índice.

\section{LITERATURA CITADA}

Bezerra, F.M.L. Coeficientes de cultura e efeitos de déficits hídricos nos diferentes estágios fenológicos sobre a produção da batata (Solanum tuberosum L.). Piracicaba: ESALQ, 1995. 131p. Tese Doutorado

Bosnjak, D.; Peijic, B. Potatoes water requirement in the Chernozem zone of Yugoslavia. Acta Horticulturae, Leuven, v.1, n.449, p.211-215, 1996.

Bosnjak, D.; Peijic, B.; Dragovik, S. Potato yield depending on evapotranspiration in the Vojvodina province. Acta Horticulturae, Leuven, v.1, n.462, p.297-301, 1997.

Doorembos, J.; Kassam, A.H. Efectos del agua sobre el rendimiento de los cultivos. Roma: FAO, 1986, 180p.

Evangelista, A.W.P. Avaliação de métodos de determinação da evapotranspiração no interior de casa de vegetação em Lavras, MG. Lavras: UFLA, 1999, 79p. Dissertação Mestrado

Fabeiro, C.; Ollalla, F.M.D.; de Juan, J.A. Yield and size of deficit in irrigated potatoes. Agricultural Water Management, Amsterdam, v.48, n.3, p.255-266, 2001.

Gandar, P.W.; Tanner, C.B. Leaf growth, tuber growth and water potential in potatoes. Crop Science, Madison, v.16, n.4, p.534-538, 1976.

Hoffman, G.; Howell, T; Solomon, K.H. Management of farm irrigation systems. St. Joseph: ASAE, 1990. 1040p.

Kashyap, P.S.; Panda, R.K. Evaluation of evapotranspiration estimation methods and development of crop-coeficients for potato crop in sub-humid region. Agricultural Water Management, Amsterdam, v.50, n.1, p.9-25, 2001.

Kincaid, D.C.; Westermann, D.T.; Trout, T.J. Irrigation and soil temperature effects on russet burbank quality. American Potato Journal, Maine, v.70, n.10, p.711-723, 1993.

Netto, A.O. Análise de crescimento na cultura da batata (Solanum tuberosum ssp. tuberosum) submetida a diferentes lâminas de irrigação: razão tubérculo parte aérea, área foliar específica, razão de área foliar e razão de massa foliar. Irriga, Botucatu, v.4, n.1, p.13-24, 1999.

Nimah, M.; Darwish, I.; Bashour, I. Potato yield response to deficit irrigation and $\mathrm{N}$ fertilization. Acta Horticulturae, Leuven, v.2, n. 537, p.823-830, 2000.

van Genuchten, M.Th. A closed-form equation for predicting the hydraulic conductivity of unsaturated soils. Soil Science Society of America Journal, Madison, v.44, p.892-898, 1980.

Zhikov, Z.; Kaltcheva S.; Irrigation of potatoes under condition of water deficit. Acta Horticulturae, Leuven, v.1, n.449, p.217-221, 1997. 